an identical manner on the opposite side of the anatomy. Ratios over 10 may be obtained. Ulcerated pigmented carcinomas involving skin give ratios under 3 . Variable uptakes have been obtained with malignant melanomas according to the degree of histological activity. Haematomas often give a value less than 1 .

Radiation suppresses phosphorus uptake and tests at intervals have been used as a control for radiotherapy of skin lesions where indicated. Values reducing to unity have been taken as ablation of active disease. ${ }^{2}$

Perhaps it might be feasible to do a radioactive-phosphorus test (minimum ratio of 5), then insert the radioactive gold before excising the lesion, so that the lymphatics are dealt with in continuity and uninterruptedly.I am, etc.,

Radiotherapy Department,

Royal Northern
London N.7.

\section{Anthony Green.}

REFERENCES 1 Green, A., Tidcock, B. M. H., and Burghes,

2 1961, p. 593. Soc. Med., 1959, 52, 482.

\section{Ice Packs for the Sore Perineum}

SIR,-The application of ice bags in order to ease pain after perineal repairs in gynaecology and obstetrics has been known for some years. The traditional bag filled with lumps of ice is messy, and has only short-lived effects because the ice is melted quickly by contact with the warm body.

For some time I have been using a sealed leak-proof bag, ${ }^{1}$ made of strong plastic, containing a chemical gel. It measures $11 \times 18 \mathrm{~cm}$. The bag is kept in a refrigerator and, when required for a patient, is inserted in a 3\% Savlon (cetrimide and chlorhexidine) solution for a few minutes, dried with a sterile towel, and, covered by a layer of gauze, it is placed in contact with the perineum It maintains its cooling and analgesic effects for 2-3 hours and can then be replaced by another bag. The bags can be used over and over again and last indefinitely. They should not be placed in the freezing compartment of the refrigerator, as its temperature may become dangerously low and burn the skin.

A larger-sized bag, measuring $18 \times 21 \mathrm{~cm}$., is also available for larger wounds and bruises.

Incidentally, the ice pack can also be used as a hot pack for application of heat by letting it simmer in hot water of the required temperature for 15 minutes.

If the pack is punctured accidentally, it can be mended easily with adhesive tape.-I am, etc.,

$$
\begin{aligned}
& \text { St. Leonards-on-Sea, BRUCE ETON. } \\
& \text { Sussex. } \\
& \text { The bag is obtainable from the manufacturers, } \\
& \text { Ice-Pak Marketing Ltd., East Street, Epsom, } \\
& \text { Surrey. }
\end{aligned}
$$

\section{Inversion of Bladder}

SiR,-I read with interest the memorandum on acute inversion of the urinary bladder in labour published by Dr. J. C. Sutherland and Dr. R. T. Merki (17 October, p. 991). From the description of the clinical findings in this case it appears that it was possible to insert a finger into the bladder posterior to the inverted pedicle. This being the case, I believe that the replacement of the inversion could have been achieved by hydrostatic pressure.
The principle of this method was originally described by James Vincent O'Sullivan in 1945 for replacement of acute inversion of the uterus and can logically be applied to the bladder.

A Foley catheter (with a large bag) should be inserted behind the pedicle into the bladder. The bag should then be blown up. Traction on the catheter would occlude the " neck" of the inversion and prevent leakage. Sterile, warm normal saline containing an antiseptic should then be instilled into the bladder through the catheter either by gravity or by gentle syringe pressure until the inversion reduces. A total of approximately $20 \mathrm{fl}$. oz. $(570 \mathrm{ml}$.) would suffice.

This method is far less traumatic than mechanical replacement, and I believe that were it attempted for inversion of the bladder rupture might be prevented.-I am, etc.,

London S.W.19.

J. C. O’Sullivan.

\section{Management of Malignancy}

SIR,-Everybody will congratulate Dr. R. G. Gibson on his outstanding article (17 October, p. 965) "Impact of Malignant Disease on the General Practitioner." His discussion on "Should the Doctor Tell ?" is particularly wise.

Owing no doubt to want of time he omitted to discuss the delay between the time the disease "gives itself away" to the patient and the first visit to the family doctor. Most of the " accessible cancers" accounting for some 24,459 deaths per year as a rule do show symptoms while still in an early stage, but are neglected by the patient. The RegistrarGeneral in 1957 drew attention to the fact that in a series of cases of carcinoma of the breast the median delay after a patient has noticed a lump before treatment is 6.2 months, and $17.3 \%$ waited over two years. The figures in the case of the uterus are 5.7 months and $8.4 \%$ waiting over two years, and $24 \%$ patients with carcinoma of rectum wait over a year.

If this ignorance concerning the importance of reporting symptoms can be removed, the family doctor would have fewer distressing cases with which to deal. The argument that cancer education would fill the surgeries with neurotics and patients suffering from cancerphobia has been disproved in many countries and in publications from Manchester.-I am, etc.,
Oxford.
Malcolm Donaldson.

\section{Spironolactone and Plasma Cortisol}

SIR,-Dr. B. L. Pentecost (4 July, p. 42) reports that a woman with rheumatic heart disease and an ischaemic kidney had been found to have a morning plasma-cortisol concentration of $156 \mu \mathrm{g} . / 100 \mathrm{ml}$. Dr. Mattingly, who did the measurements, suggested that this remarkable figure might be related in some way to the spironolactone which the woman was taking.

We have found a close association between Aldactone-A (spironolactone) therapy and grossly elevated plasma-cortisol levels. The rise is apparent only, and it is not due to spironolactone, the active principle of Aldactone-A, but to other material present in the tablets. Plasma cortisol is estimated here by a method ${ }^{1}$ closely related to that used by Dr. Mattingly. ${ }^{2}$ Our 10 a.m. normal values are in a similar range to his-namely, from 5 to $25 \mu \mathrm{g} . / 100 \mathrm{ml}$. plasma.

Volunteers from the hospital staff were asked to swallow $25 \mathrm{mg}$. of spironolactone, either pure or as Aldactone-A, immediately after giving a control blood sample. Further blood samples were drawn throughout the same day and their cortisol content measured. It was found that pure spironolactone caused no change in the apparent plasma concentration of cortisol. One Aldactone-A tablet, however, caused a brisk increase to a maximum of from 45 to $85 \mu \mathrm{g} . / 100 \mathrm{ml}$. two or three hours later.

The rise in the plasma cortisol was apparent and not real for the following reasons :

(1) The urinary excretion of cortisol metabolites was not altered after one week's Aldactone-A therapy. This means that the adrenal gland was not stimulated by the drug to secrete increased amounts of cortisol.

(2) The increase occurred promptly after the ingestion of a single tablet, and so cannot be explained by postulating a change in the proteins which bind cortisol. Cortisolbinding proteins do increase in response to oestrogen therapy, but the change is a slow one, taking some days for the maximum effect to develop. Furthermore, oestrogen-induced cortisol levels rarely rise above $50 \mu \mathrm{g} . / 100 \mathrm{ml}$. plasma.

(3) The substance measured disappears from the blood-stream at a rate two to five times slower than cortisol. This fact alone makes it unlikely that cortisol is being measured and suggests that Aldactone- $A$ contains a substance which interferes with the fluorimetric method for estimating cortisol.

Recently the composition of Aldactone-A has been changed. The ingredients common to both new and old tablets are spironolactone, colouring matter, and magnesium stearate. Both types of tablet cause a rise in apparent cortisol levels, the old tablet (issued before 22 May 1964) probably to higher levels than the new. Spironolactone has been eliminated as a cause of interference. Thus the source of interference must be either the dyes used to colour the tablets or magnesium stearate.-I am, etc.,

\section{Medical Unit, \\ The Princess Margaret Hospital \\ Christchurch, New Zealand.}

\section{REFERENCES}

1 De Moor, P., Raskin, M., and Steeno, O., Ann. 2 Mattingly, D., F. clin. Path., 1962, 15, 374.

\section{Ignorance of Drug Costs}

SIR,-To show how little idea average patients understand about the cost of the drug treatment they may be receiving, a woman patient of mine under treatment with a combined preparation of P.A.S. and isoniazid for pulmonary tuberculosis as an out-patient ran out of her treatment before her next appointment, and went to the chemist and asked for a supply which, to her astonishment, would have cost her in the region of $£ 313 \mathrm{~s}$. She hastily withdrew and fixed an early appointment to see me. Since then she has been going about and telling her friends of her 